\title{
Palácio Gustavo Capanema: estrutura $\in$ construção
}

\author{
DANIELLI CRISTINA BORELLI CINTRA - DR ${ }^{a}$. MSc. ENG. CIVIL \\ https://orcid.org/0000-0003-4246-894X \\ Instituto do Patrimônio Histórico e Artístico Nacional / IPHAN-RJ
}

\author{
JOÃO LEGAL LEAL - ARQUITETO URBANISTA \\ Instituto do Patrimônio Histórico e Artistico Nacional / IPHAN-RJ
}

\author{
LEANDRO CAMPOS - MSc. ARQUITETO URBANISTA \\ JORGE A. SCHNEIDER - ENGENHEIRO CIVIL - DIRETOR \\ Qualtech Engenharia Ltda.
}

\begin{abstract}
RESUMO
RECONHECIDO COMO OBRA PIONEIRA DA BEM-SUCEDIDA PARCERIA ENTRE A ES-

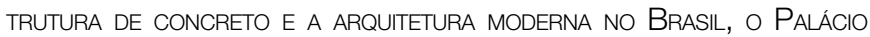
Gustavo CaPAnema fol construído entre 1937 e 1945, PARA SER a SEDE do Ministério da EdUCAÇÃo E Saúde dURANTE O PRIMEIRO GOVERNO dE GetúlioVARGAS (1930-1945). As INOVAÇÕES EXPRESSIVAS E COM REPERCUSSÃO INTERNACIONAL COMO O PROJETO ESTRUTURAL ELABORADO POR EMÍLIO BAUMGART E O ESTUDO DO CONTROLE DA RESISTÊNCIA DO CONCRETO DA OBRA
\end{abstract}

desenvolvido pelo Prof. Lobo Carneiro fazem com que o Palácio GustAVO CAPANEMA SEJA UM EXEMPLO PIONEIRO DA TECNOLOGIA CONSTRUTIVA DE EDIFÍCIOS NAS DÉCADAS DE 1930 E 1940. O OBJETIVO DO TRABALHO É APRESENTAR OS DESAFIOS CONSTRUTIVOS E DE PROJETO ESTRUTURAL, COM DESTAQUE PARA A ANÁLISE DA LAJE COGUMELO INVERTIDO. A PESQUISA FOI REFERÊNCIA PARA OS PROJETOS DA ATUAL OBRA DE RESTAURAÇÃO, CONSERVAÇÃO E MODERNIZAÇÃO DAS INSTALAÇÕES DO EDIFÍCIO, MAIOR INTERVENÇÃO DE SUA HISTÓRIA.

Palavras-chave: concreto armado, Emílio Baumgart, Lobo Carneiro, laje cogumelo invertido, Palácio Gustavo Capanema.

\section{INTRODUÇÃO}

$\left\{\begin{array}{l}\text { econhecido internacional- } \\ \text { mente, o Palácio Gustavo } \\ \text { Capanema (Figura 1) é consi- }\end{array}\right.$ derado como o marco inicial da arquitetura moderna no Brasil, no qual as possibilidades plásticas do concreto foram exploradas de modo pioneiro, impulsionando tantas obras que vieram depois (COSTA, 2005). De uso institucional, situado no centro do Rio de Janeiro, é tombado pelo Instituto do Patrimônio Histórico e Artístico Nacional, desde 1948 (IPHAN, 1948).

Foi construído entre 1937 e 1945 para ser a sede do Ministério da Educação e Saúde durante a gestão do então ministro Gustavo Capanema no primeiro governo de Getúlio Vargas (1930-1945)1. Apresentou pela primeira vez algumas das características da arquitetura moderna em sua vertente corbusiana, como o uso de pilotis, planta livre, terraço-jardim, fachada livre de paredes e vedação contínua em vidro (curtain wall) (LISSOVSKY; SÁ, 1996). O seu projeto reuniu arquitetos renomados como Lúcio Costa, Oscar Niemeyer, Affonso Reidy, Carlos Leão, Ernany Vasconcelos e Jorge Machado Moreira, com a consultoria de Le Corbusier. Artistas como Burle Marx, Cândido Portinari, Bruno Giorgi, Adriana Janacópulus, Celso Antônio e Jacques Lipchitz foram responsáveis pelas artes integradas ao edifício como pinturas, esculturas, painéis de azulejos e paisagismo. O projeto estrutural foi desenvolvido por Emílio Baumgart entre 1937 e 1938.

\section{I.I Características do Palácio Gustavo Capanema}

A edificação se define por dois corpos, ambos sobre pilotis, aprumados e perpendiculares entre si (Figura 2). O mais alto, de forma retangular, com 16 pavimentos, medindo 21,45 $\mathrm{m}$ por $68,56 \mathrm{~m}$ e altura de $82,25 \mathrm{~m}$, disposto na direção leste-oeste, paralelo à Rua Araújo Porto Alegre, corresponde ao bloco administrativo. O volume mais baixo, transversal, no sentido norte-sul,

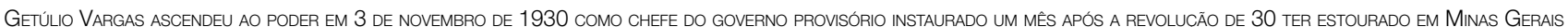

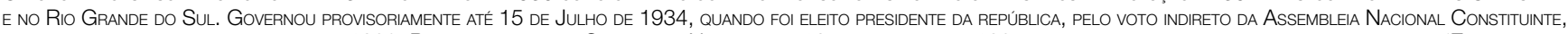

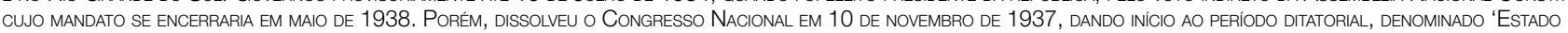
NOVO', QUE PERDUROU ATÉ OUTUBRO DE 1945, QUANDO FOI DEPOSTO, DOIS MESES ANTES DAS ELEIÇÕES PREVISTAS, APÓS QUASE 15 ANOS NO PODER, FINALIZANDO ASSIM SEU PRIMEIRO GOVERNO. RETORNOU À PRESIDÊNCIA, PELA VIA DEMOCRÁTICA, EM 1951, COM MANDATO INTERROMPIDO EM 1954, APÓS TER SE SUICIDADO NA MANHÃ DE 24 DE AGOSTO.
} 
com a parte sul de forma retangular medindo $50,55 \mathrm{~m}$ por $24,40 \mathrm{~m}$ e com $12,10 \mathrm{~m}$ de altura, consiste na área de exposições. Já o trecho norte, que abriga os auditórios, é configurado por um trapézio de 23,20 m na base menor, e $25,80 \mathrm{~m}$ na base maior, por $14,40 \mathrm{~m}$ de comprimento, com 15,85 m na sua maior altura. O edifício totaliza 27.547 $\mathrm{m}^{2}$, sendo $24.154 \mathrm{~m}^{2}$ de área coberta e $3.382 \mathrm{~m}^{2}$ de área descoberta.

O corpo principal do bloco administrativo é definido nas duas fachadas por esquadrias metálicas. A fachada norte apresenta guarda-corpo em alvenaria e esquadrias protegidas da insolação por brise-soleil. Já, a fachada sul apresenta esquadrias de piso a teto (curtain wall), caracterizando de forma pioneira no mundo o uso de fachada totalmente envidraçada em edifício (SEGRE; BOAS; SOUZA, 2009). Toda a caixilharia metálica é belga, em aço-carbono AISI-1010, somando $4.222 \mathrm{~m}^{2}$, e se abre manualmente por um sofisticado sistema de contrapesos no interior da caixilharia, possibilitando a ventilação natural cruzada.

Sem dúvida, os brise-soleil articuláveis da fachada norte constituem um dos elementos mais originais do edifício, cuja estrutura foi projetada por Emílio Baumgart (1890-1943). Por protegerem toda a fachada do sol, dispensam a instalação de persianas ou cortinas junto às esquadrias, o que viabiliza a desejável ventilação cruzada, expressa na concepção do projeto arquitetônico. Os brises em placa de fibrocimento foram instalados numa grelha de mainéis verticais e horizontais de concreto armado, acompanhando a modulação das esquadrias, com 5,00 m x 2,00 m, e 1,30 $\mathrm{m}$ de profundidade. As placas foram pintadas da cor azul céu, conforme definição de Lucio Costa. As três lâminas de brises em cada pavimento (no $2^{\circ}$ pavimento, que apresenta
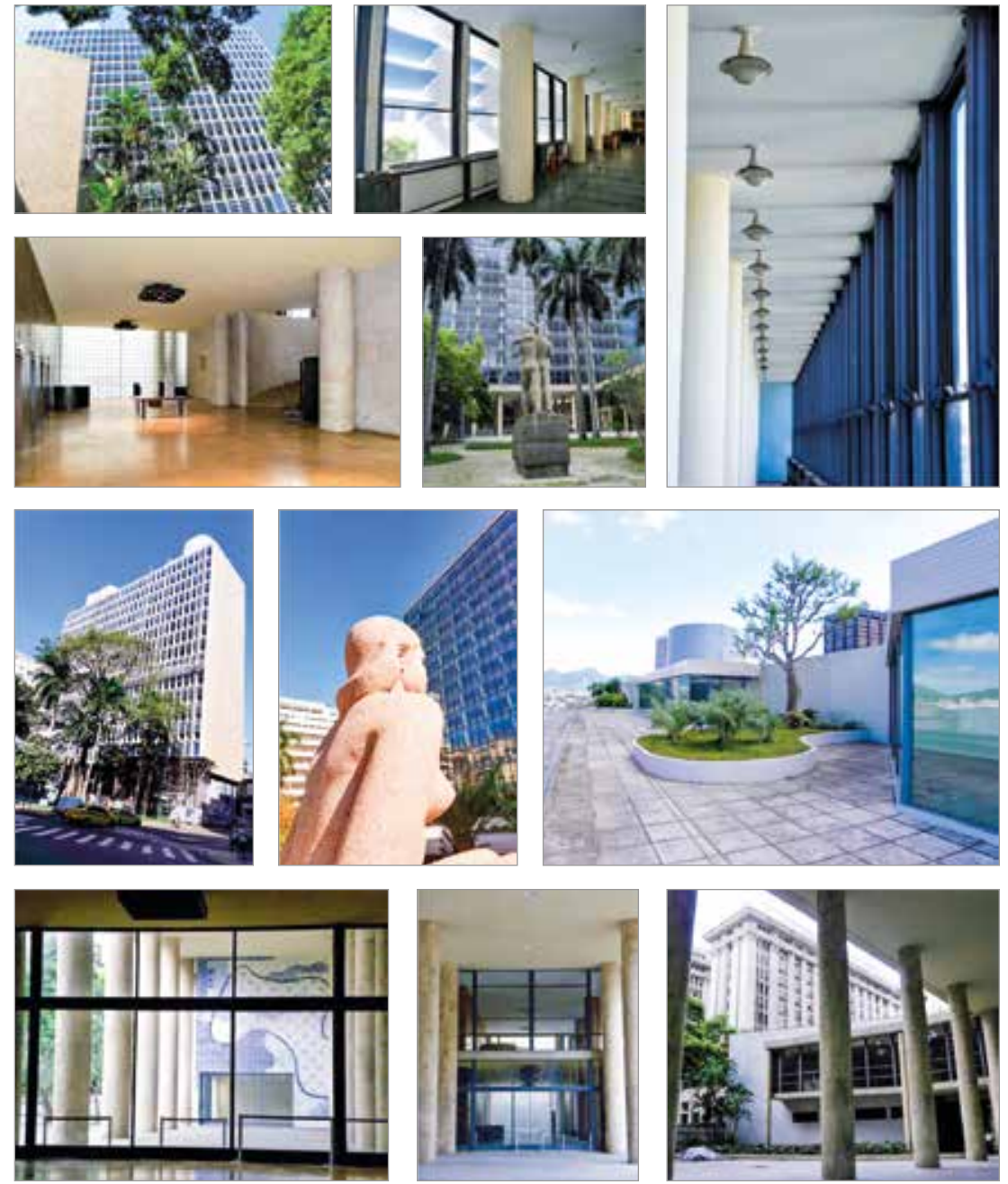

Figura 1

Palácio Gustavo Capanema, por Leal (2018): fachadas, pilotis e interior do edifício

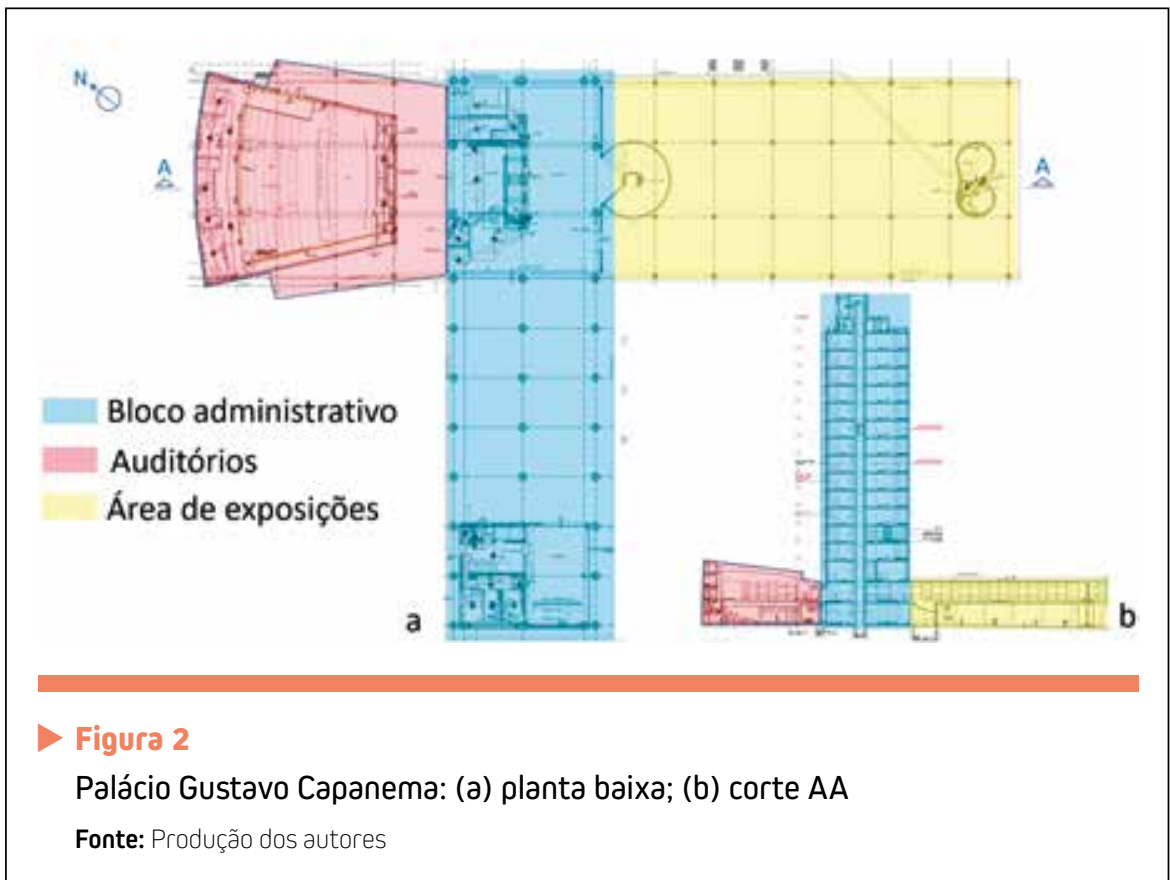




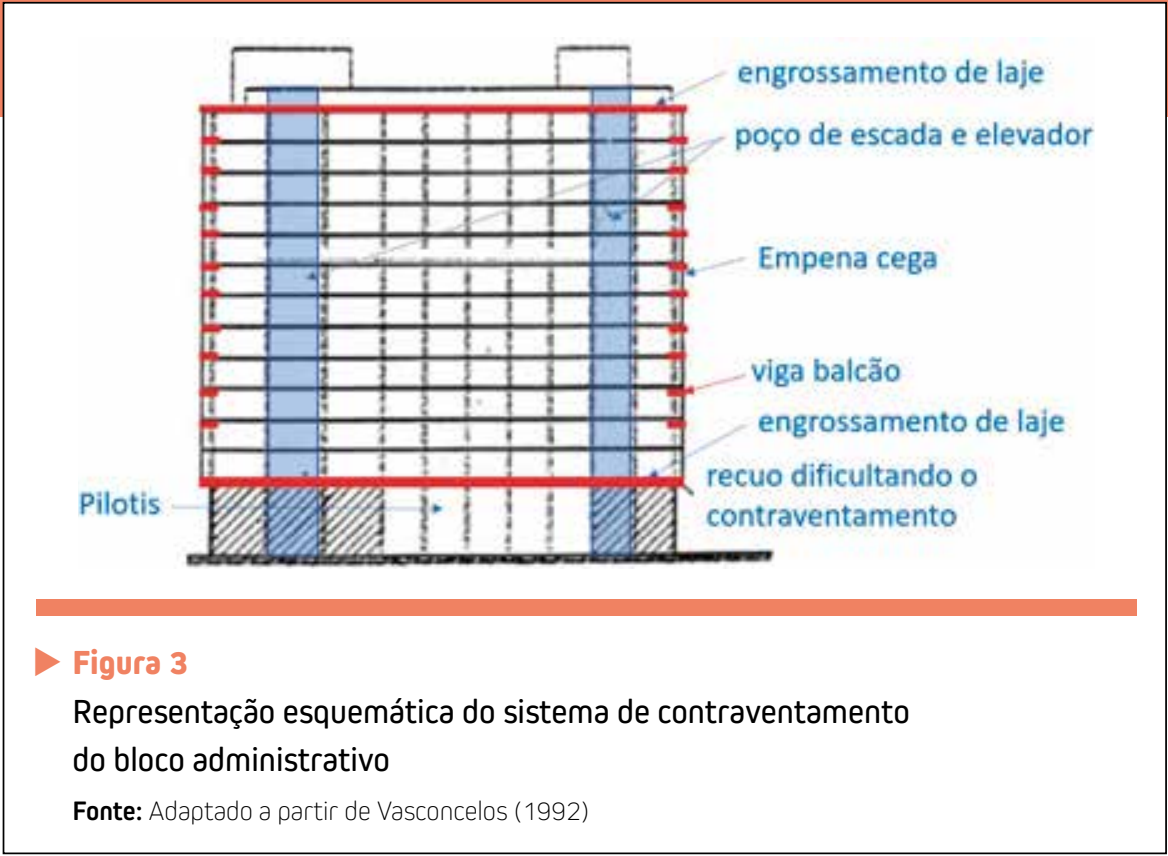

pé-direito maior, são 4) se articulam em um caixilho de aço, que é acionado manualmente por meio de uma alavanca metálica, a partir do interior do pavimento.

\section{I.2 Concepção da estrutura}

Entre os componentes do caráter inovador do Palácio Gustavo Capanema encontra-se o sistema estrutural em concreto armado. O projeto de Emílio Baumgart permitiu a imagem de leveza do prédio, com o afastamento das colunas em relação aos planos das fachadas, situando-as no interior da lâmina vertical e no exterior do salão de exposições, favorecendo futuras adaptações de uso (COSTA, 1936).

Nesse sentido, foi elaborada uma solução de sustentação baseada em colunas e lajes, onde em vez de vi- gas, colocava-se sobre cada coluna um capitel invertido, denominado piltz-decken, imerso na espessura total da laje de $26 \mathrm{~cm}$ e, mantendo nos trechos intermediários, a espessura de $16 \mathrm{~cm}$, o que deixou $10 \mathrm{~cm}$ livres da espessura para enchimento e a passagem das instalações. O sistema de colunas moduladas com vãos de 6 a 8 m, situadas no interior da lâmina alta, duplicam-se nos extremos das duas empenas para se contrapor à ação do vento. Esta estrutura leve, para a sustentação da lâmina alta, é reforçada pelos pilares robustos de concreto que delimitam as caixas dos elevadores e das escadas, situados nos extremos leste e oeste do volume principal.

No bloco do salão de exposições, com a finalidade de diferenciar a imagem de leveza da lâmina vertical e acen-

tuar a aparência de peso do volume horizontal baixo, as colunas de $\varnothing 60 \mathrm{~cm}$ estão colocadas no exterior, apoiando as lajes por meio de consolos.

Assim, em função das características ligadas ao conforto ambiental e ao uso de soluções tecnológicas inovadoras, o edifício do Palácio Gustavo Capanema, à época de sua inauguração na década de 1940, foi o mais moderno edifício do Brasil (SEGRE; BOAS; SOUZA, 2009).

O objetivo do presente artigo é apresentar os desafios construtivos e de projeto estrutural, como o sistema de contraventamento, pilotis com pé direito de $10 \mathrm{~m}$, a condução da carga das empenas para os pilares afastados da fachada, a cobertura em casca do auditório, o carregamento diferenciado da laje da biblioteca, além da readequação de projeto para atender a uma demanda de ampliação de quatro pavimentos durante a etapa de construção, com destaque para a análise estrutural da laje cogumelo invertido e o estudo do controle da resistência do concreto, desenvolvido pelo Prof. Lobo Carneiro. Atualmente, ocorre a maior intervenção da história do Palácio Gustavo Capanema, com as obras de restauração, conservação e modernização das instalações do edifício, cujos projetos utilizaram como referência as informações aqui apresentadas.

\section{PROJETO ESTRUTURAL}

\section{I Bloco administrativo}

O bloco administrativo é um edifício de 16 pavimentos, com lajes cogumelo de capitel invertido, pilotis da ordem de $10 \mathrm{~m}$ de altura e fundação com sapatas assentadas a cerca de $2 \mathrm{~m}$ de profundidade. Inicialmente projetado para 12 pavimentos, durante a obra ocorreu o acréscimo de outros 4 pavimentos

Figura 4

Planta esquemática do $3^{\circ}$ pavimento

Fonte: Produção dos autores 
(LAURD, 2009), com a devida verificação e adaptação do projeto.

No sistema de contraventamento (Figura 3), o pilotis interrompe a ligação lateral dos elementos da estrutura, dificultando a distribuição horizontal das cargas nos primeiros pavimentos. Nessa região, as paredes da empena lateral foram recuadas, interrompendo a ligação com as fundações, que seria a solução imediata para resistir às ações do vento. Baumgart, então aproveitou a enorme rigidez horizontal das lajes para transferir as forças decorrentes da ação do vento para os núcleos rígidos formados pelos poços dos elevadores e escadas, situados próximos aos extremos. O raciocínio de Baumgart, hoje genericamente difundido e aplicado nas obras correntes, foi uma grande novidade na época, mais uma demonstração da sua genialidade (VASCONCELOS, 1992).

Os robustos capitéis de lajes cogumelo não se adaptavam às espessuras reduzidas requeridas pelo projeto arquitetônico e não havia maneira de esconder as vigas entre pilares, cujos vãos são de $8 \mathrm{~m}$ a $6 \mathrm{~m}$. Então, Baumgart teve a ideia de substituir os capitéis normalmente concebidos abaixo da laje, daí o termo "cogumelo", pelo engrossamento da laje na face superior. O denominado cogumelo invertido manteve a condição de teto liso exigido pela arquitetura, garantindo ao mesmo tempo a resistência à punção das lajes. Os espaços vazios entre capiteis seriam preenchidos com material inerte e leve, permitindo o livre trajeto das instalações. Foi a primeira vez que se usou no Brasil esse tipo de laje cogumelo, cujo dimensionamento se desenvolveu em total desacordo com as normas da época (VASCONCELOS, 1992).

Parte da área do $4^{\circ}$ pavimento foi projetada para receber cargas de es-

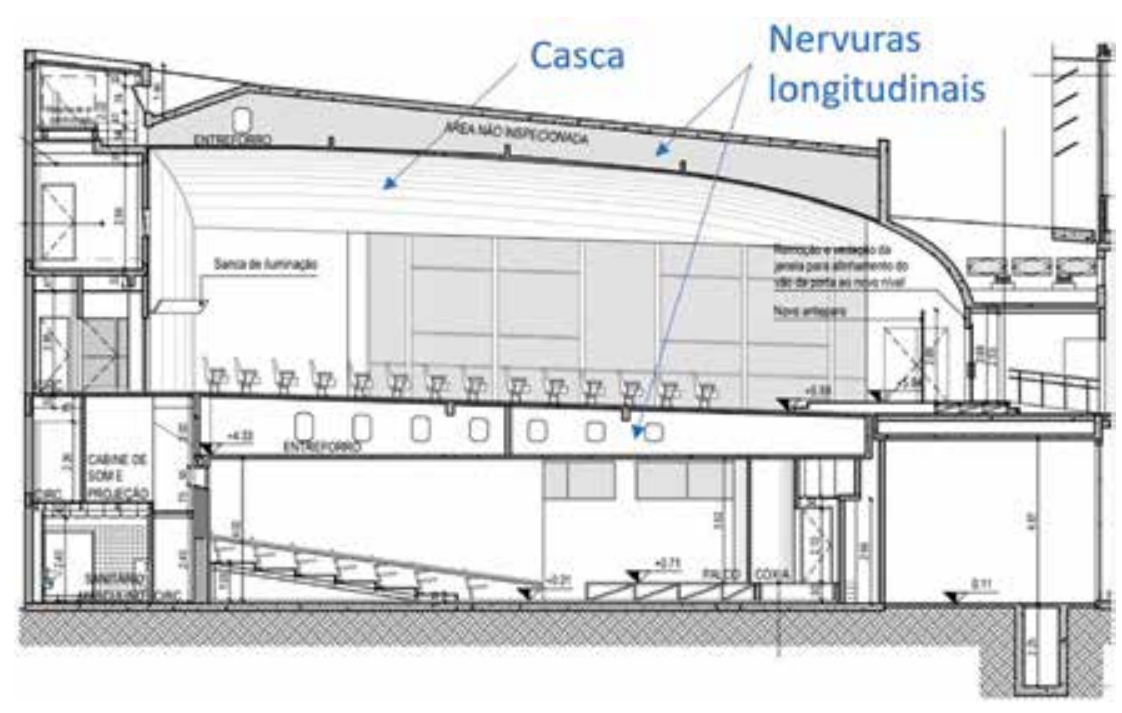

\section{Figura 5}

Corte longitudinal do bloco de auditórios, adaptado de projeto arquitetônico

Fonte: Astorga (2020)

tantes de biblioteca. Assim, a laje recebeu o apoio extra de cinco paredes estruturais esbeltas, indicadas em azul na Figura 4, para melhorar a distribuição das cargas entre o $3^{\circ}$ e $4^{\circ}$ pavimentos.

Em 1937, um engenheiro alemão, Adolf Kleinlogel, considerado um dos grandes nomes do concreto armado, veio ao Brasil conferir a boa reputação das construções brasileiras e ficou impressionado com as proporções e elegância das colunas recém-cons- truídas. Em 1944, o engenheiro norte americano, Arthur Boase, membro do comitê normativo americano, veio ao Brasil e também se impressionou com a esbeltez das colunas. Concluiu que um edifício similar ao bloco administrativo consumiria cerca de $30 \%$ a mais de concreto, $25 \%$ a mais de aço e o custo dos pilares seria $60 \%$ mais alto se a estrutura fosse projetada pelas normas dos Estados Unidos (COSTA, 2005).

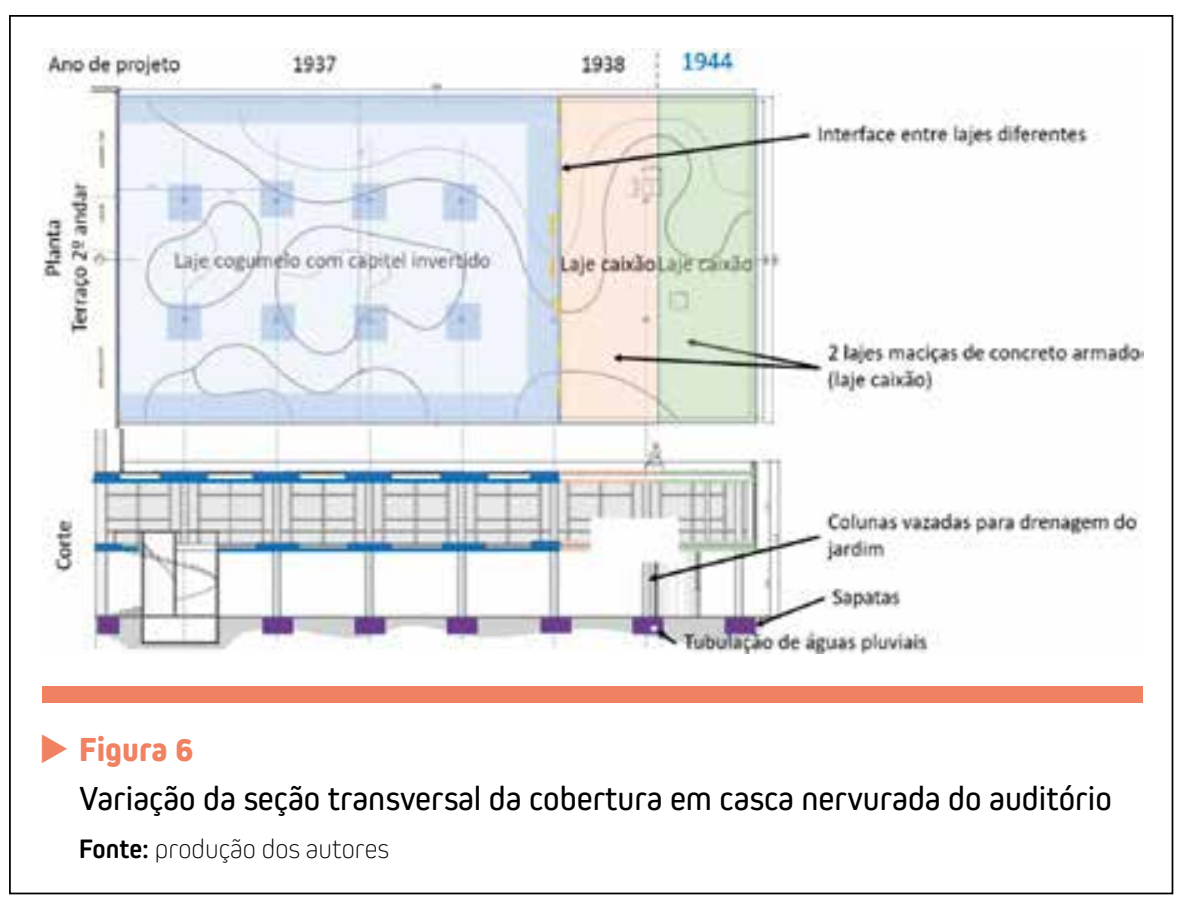




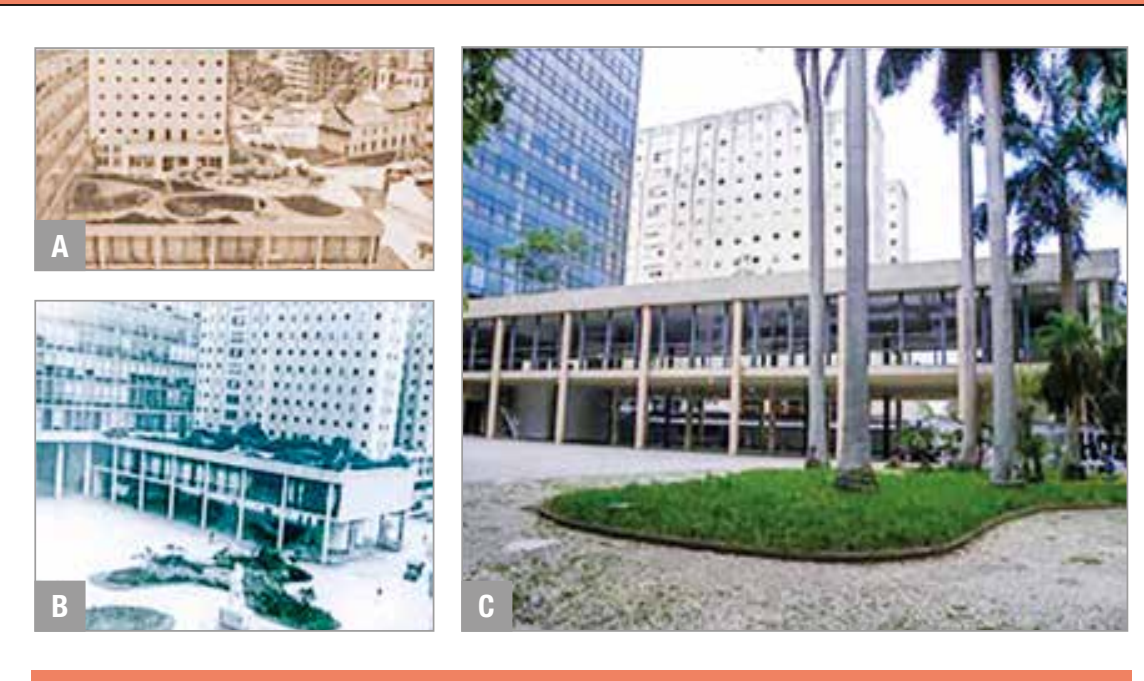

Figura 7

Jardim do terraço do segundo pavimento e área de exposições:

(a) imagem de 1944, com 6 vãos, acervo do Arquivo Central do Iphan/RJ;

(b) imagem com 7 vãos, autor desconhecido [1945?], acervo do Arquivo

Central do Iphan/RJ; (c) aspecto atual com 7 vãos, por Leal (2018)

\section{2.? Auditórios}

O bloco de auditórios contempla um auditório no pavimento inferior e outro no superior. A estrutura consiste em uma laje de piso nervurada, tipo caixão, e a cobertura em casca nervurada unidirecional de seção e vão variáveis, também tipo caixão (Figura 5). A parte posterior do bloco para uso de área técnica tem estrutura em pórtico, com lajes maciças.

\section{3 Área de exposições}

O bloco da área de exposições consiste num pilotis, a sala de exposição no pavimento superior e um terraço-jardim. Inicialmente projetado com 5 vãos em laje, com capitel invertido.

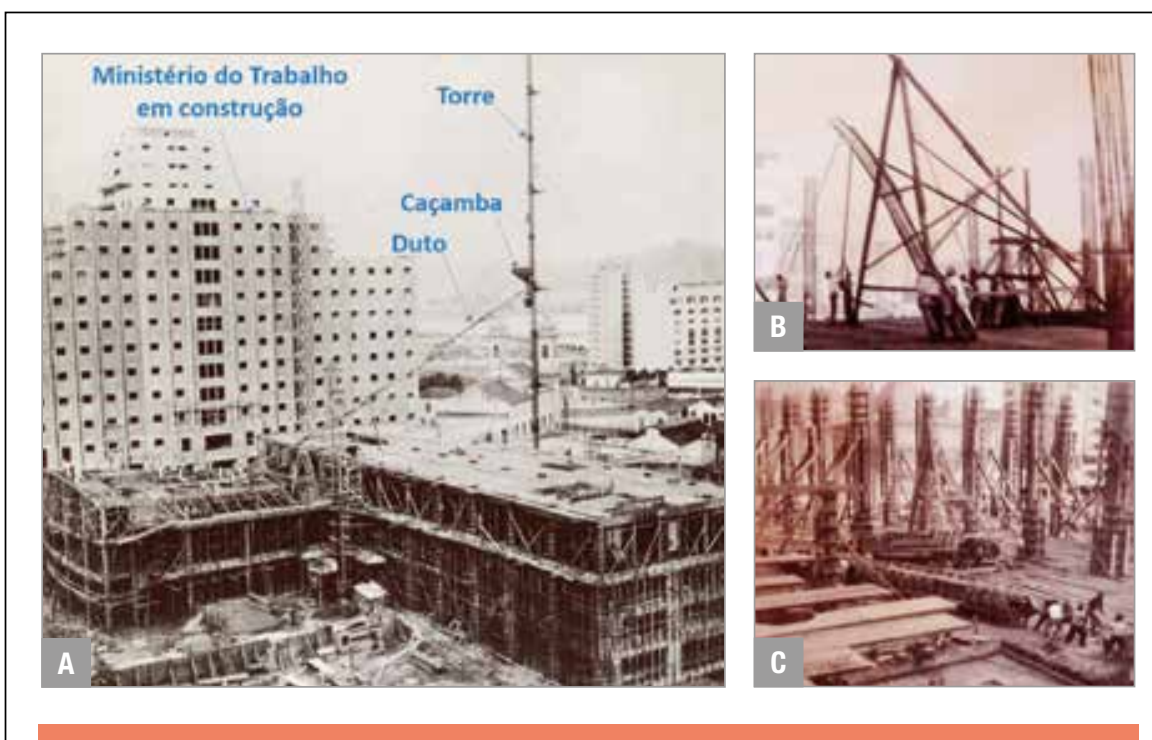

\section{Figura 8}

Processo construtivo: (a) concretagem da cobertura do bloco de auditórios; (b) suspenção da armadura dos pilares nos pavimentos; (c) montagem das fôrmas no pilotis

Fotos: Acervo do Arquivo Central do Iphan/RJ
O bloco da área de exposições teve ampliação de um vão ainda durante a obra, que também foi objeto de projeto de Emílio Baumgart, em 1938, em laje nervurada unidirecional, tipo caixão (Figura 6).

Em 1944, portanto, antes da inauguração do edifício que ocorreu em 1945, foi acrescido um outro vão ao salão de exposições e um volume solto no térreo, de formas sinuosas, aproveitando o fechamento da rua Pedro Lessa, com o intuito de permitir um acesso direto ao terraço-jardim do gabinete do ministro para os trabalhos de manutenção das áreas verdes (LAURD, 2009). Esse último vão também foi construído com laje tipo caixão, completando os sete vãos que se mantém até os dias atuais (Figura 7). A drenagem do jardim é conduzida pelos pilares internos vazados até a galeria subterrânea de águas pluviais.

\section{PROCESSO CONSTRUTIVO}

Os desafios enfrentados no desenvolvimento do projeto estrutura foram estendidos para o processo construtivo, que atendeu satisfatoriamente às adversidades de trabalho com elementos robustos, com alta taxa de armadura e em alturas elevadas, como pode ser observado no amplo registro fotográfico da obra. $\mathrm{O}$ processo construtivo foi vastamente documentado e divulgado para demonstrar a solidez e ascensão do Estado Novo, pela afirmação da arquitetura moderna e demonstração de sua viabilidade, além de refutar as críticas provocadas pela construção morosa e que rompia com os padrões estéticos então estabelecidos (MARTINELLI, 2017). Com a intervenção em andamento, é possível constatar que as especificações de projeto foram fielmente atendidas durante o processo construtivo. 


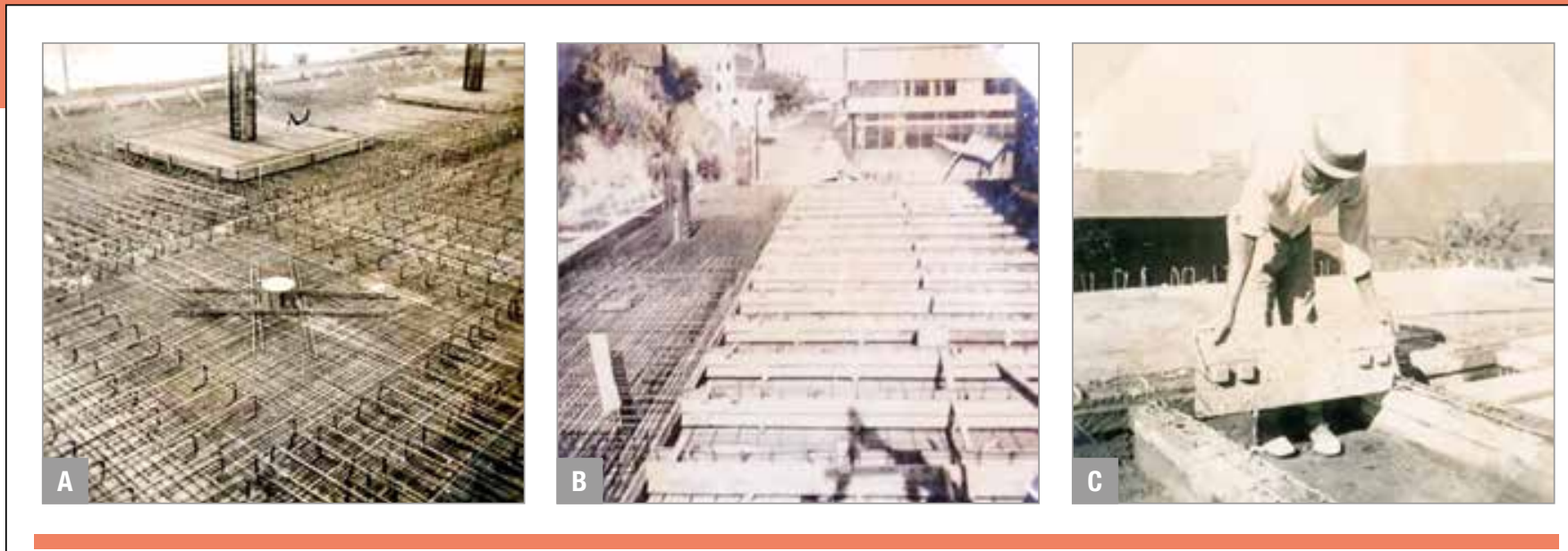

Figura 9

Montagem das lajes: (a) tipo cogumelo, com capitel invertido ou piltz-decken; (b) nervurada, tipo caixão;

(c) fechamento da laje tipo caixão com placas pré-moldadas

Fotos: Acervo do Arquivo Central do Iphan/RJ

\section{I Estrutura}

Na época da construção não existiam bombas de concreto, assim, o concreto era misturado no térreo e subia por elevador numa caçamba até um pouco acima do nível do pavimento a ser concretado. O concreto era então despejado em dutos inclinados e articulados para o lançamento do concreto nas fôrmas (Figura 8a). A Figura 8b ilustra a montagem da armadura de pilar sobre laje e a Figura 8c, o posicionamento das armaduras dentro de fôrmas em madeira dos pilares do pilotis.
Na Figura 9a, observa-se o pequeno espaçamento entre barras da armadura inferior das lajes, o reforço na espera de abertura para luminária do teto inferior e a área de capitel densamente armada, a fim de resistir aos esforços de punção. A Figura 9b ilustra a montagem da laje tipo caixão da primeira ampliação do bloco da área de exposições. O fechamento da laje tipo caixão com placas pré-moldadas apoiadas em nervuras de concreto é apresentado Figura 9c.

A Figura 10a ilustra o lançamento do concreto por meio do duto de concretagem e o espalhamento do mate- rial com aspecto pouco consistente, no piso do $3^{\circ}$ pavimento, com o capitel prolongado de base para parede estrutural. Na Figura 10b, observa-se a concretagem no $4^{\circ}$ pavimento de parede estrutural do pavimento inferior. A Figura 10c apresenta a montagem da armadura das nervuras longitudinais da cobertura do bloco de auditórios.

\subsection{Enchimento das lajes}

Após a concretagem das lajes, o espaço entre a saliência dos capitéis foi utilizado para o caminhamento das
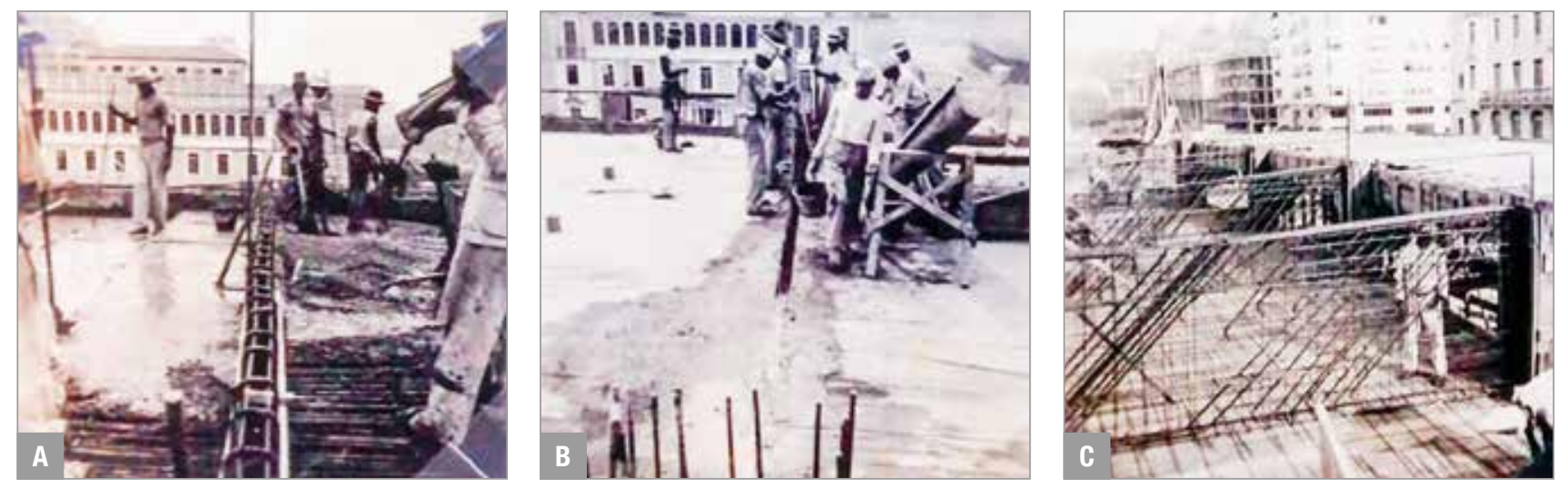

Figura 10

Elementos diversos: (a) concretagem da laje do $3^{0}$ pavimento; (b) concretagem de parede estrutural pelo nível superior; (c) montagem de armadura no auditório

Fotos: Acervo do Arquivo Central do Iphan/RJ 

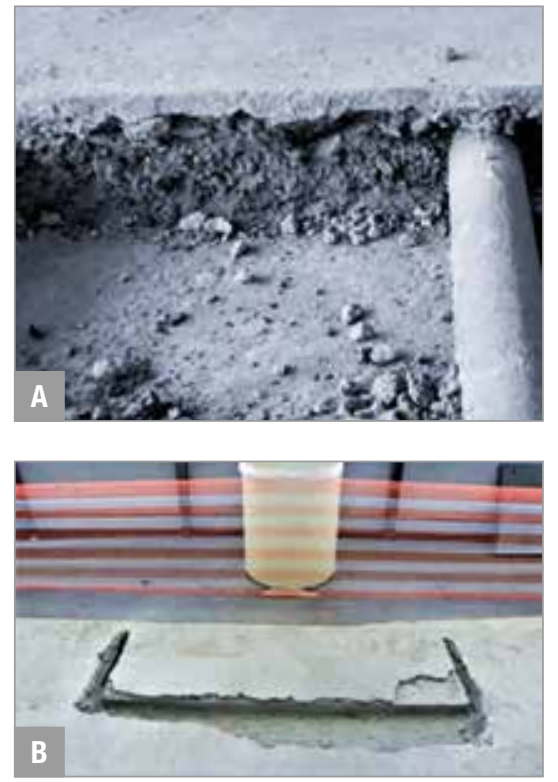
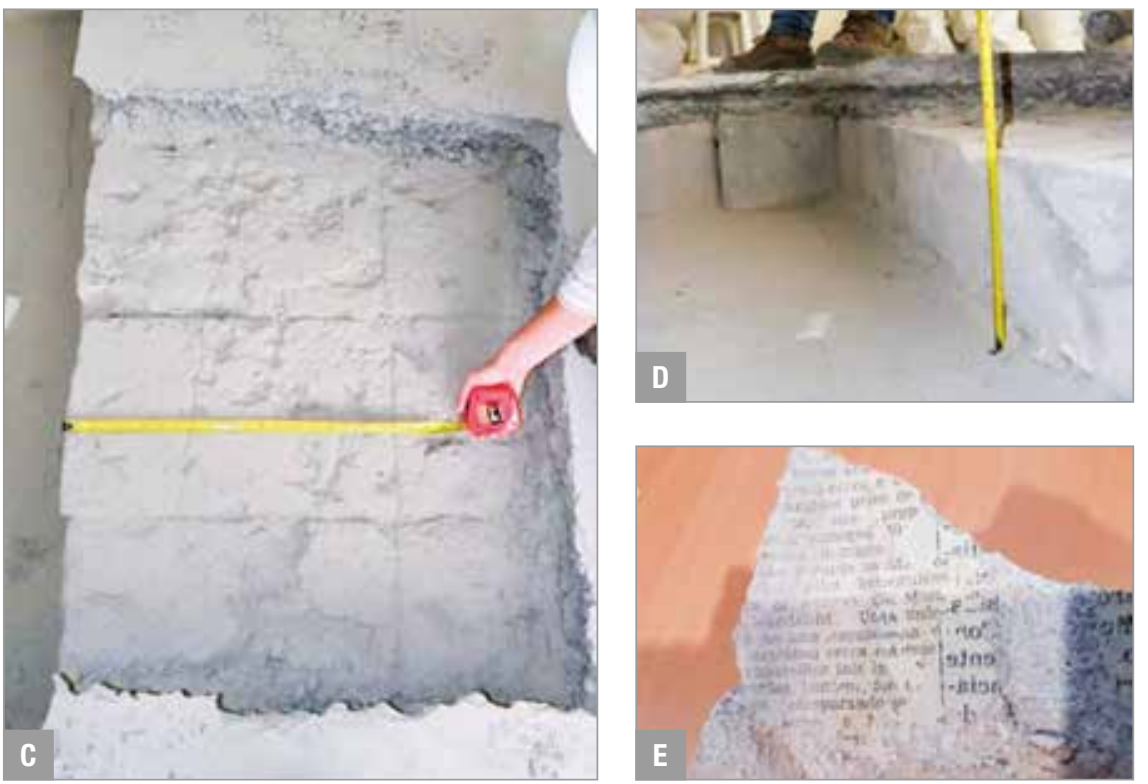

\section{Figura 11}

Prospecção em lajes, por Leal (2020): (a) tubulação embutida em enchimento com argamassa de carvão; (b) contorno de capitel; (c) enchimento em bloco celular do $2^{0}$ pavimento; (d) capitel do $2^{0}$ pavimento, (e) fragmento de jornal da época da construção colado em bloco celular

instalações de piso (Figura 11), para tomadas de elétrica, telefonia e comunicação interna, além de dutos para iluminação do teto inferior. A fim de nivelar a face superior dos capiteis com o material mais leve possível, foi em- pregada uma camada de $10 \mathrm{~cm}$ de enchimento de argamassa produzida com carvão vegetal. Em alguns pavimentos, foram utilizados fragmentos de cortiça misturados ao carvão. Em seguida, era feita uma camada de ar-

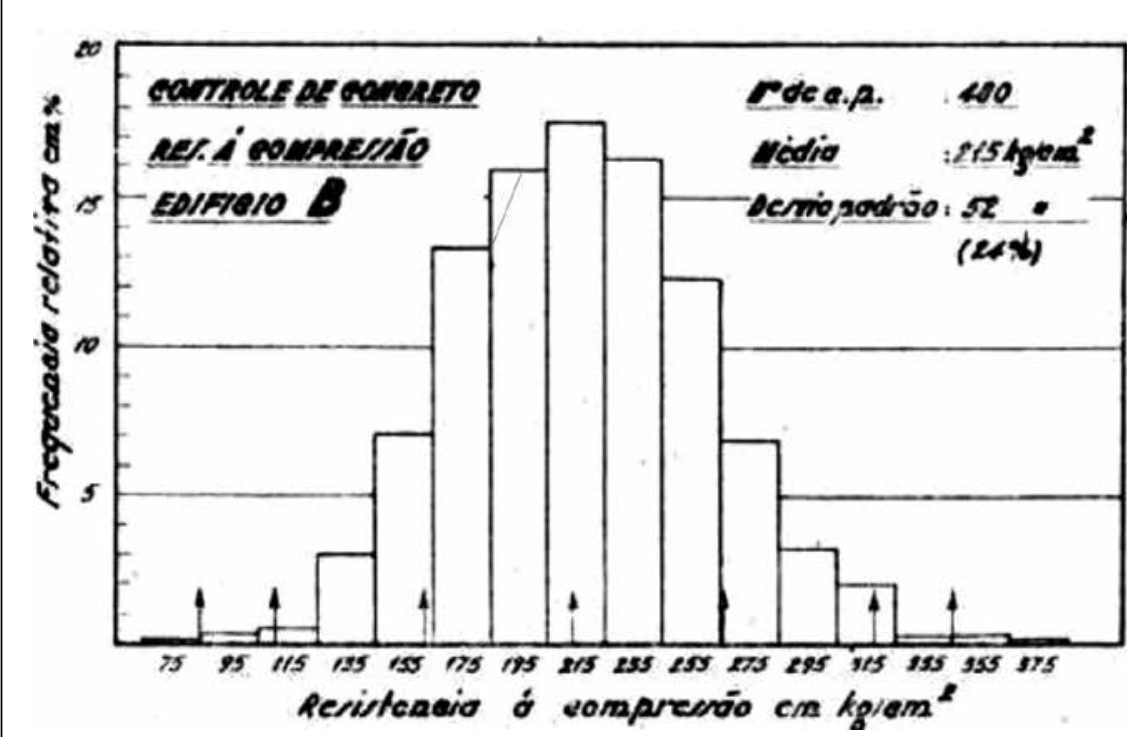

Figura 12

Distribuição de frequência (\%) de resistências à compressão $\left(\mathrm{kgf} / \mathrm{cm}^{2}\right)$ de 480 corpos de prova moldados com o concreto da obra do Palácio Gustavo Capanema Fonte: Carneiro (1944) gamassa de contrapiso para receber o revestimento de piso.

Na laje do segundo andar, com capitéis de $30 \mathrm{~cm}$, foram utilizados blocos de concreto celular como enchimento. Numa prospecção, foram encontrados fragmentos de jornais da época da construção colados aos blocos, relatando episódios da 2a Guerra Mundial e eventos esportivos do Rio de Janeiro. No piso do décimo sexto pavimento, foi empregada laje tipo caixão, com espessura de cerca de $60 \mathrm{~cm}$, com nervuras unidirecionais em alvenaria de tijolos cerâmicos. Na cobertura do décimo sexto, também foi utilizada uma laje tipo caixão, porém, com espessura menor do que a do piso.

\subsection{Controle da resitência do concreto}

Na década de 1940, o Prof. Lobo Carneiro estabeleceu um critério estatístico para o controle da resistência do concreto em obras, cujos conceitos sobre a tensão admissivel do concreto foram incorporados pela norma NB1 (ABNT, 1946). Utilizou uma imensa quantidade 


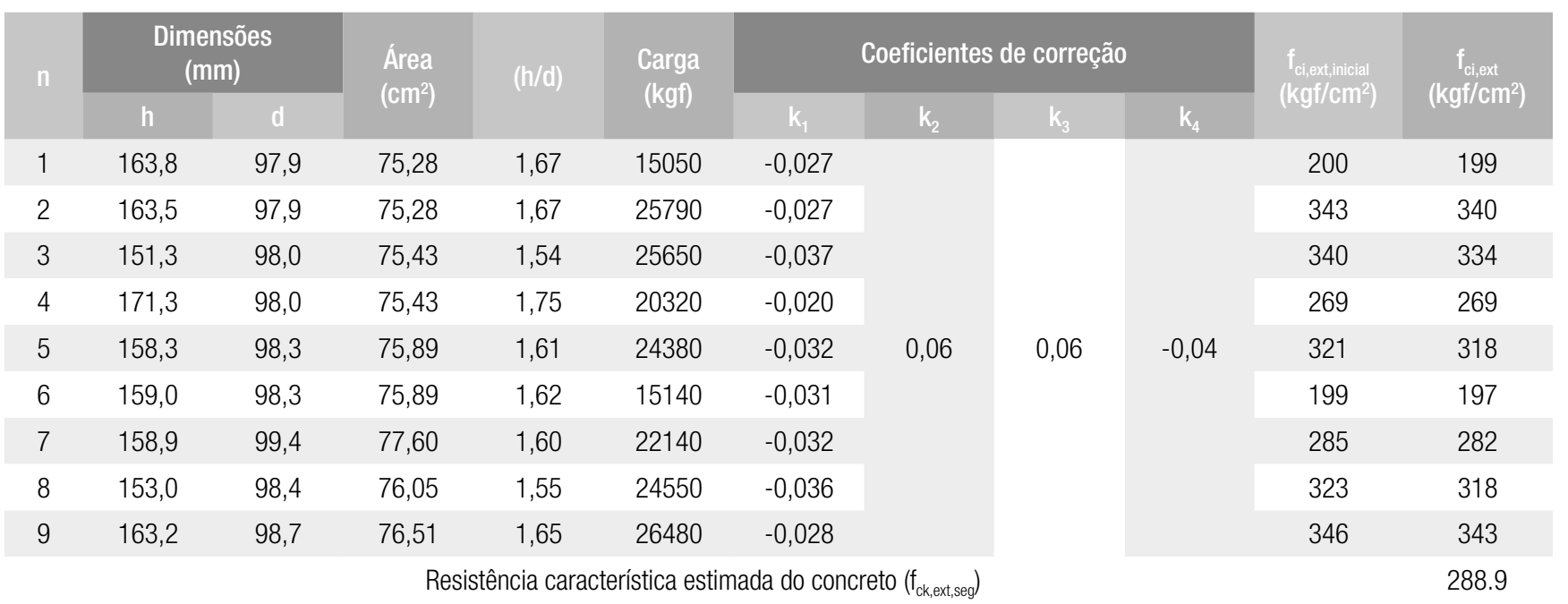

de resultados experimentais acumulada em pesquisas do Instituto Nacional de Tecnologia.

Uma das amostras desse estudo corresponde ao concreto da obra do Palácio Gustavo Capanema (THOMAZ, 2015), compreendendo 480 corpos de prova rompidos à compressão. $\mathrm{O}$ concreto foi dosado para 200 kgf $/ \mathrm{cm}^{2}$, com resistência requerida em projeto de $180 \mathrm{kgf} / \mathrm{cm}^{2}$ (CARNEIRO, 1944). A resistência média obtida aos 28 dias foi de $215 \mathrm{kgf} / \mathrm{cm}^{2}$, com desvio padrão de 52 kgf/cm² e coeficiente de variação de 24\% (Figura 12).

Oportunamente às obras de restauração e adaptação de uso em andamento, foi avaliada a resistência atual do concreto por meio do ensaio à compressão axial em nove testemunhos cilíndricos de $\varnothing 10 \mathrm{~cm}$, extraídos da laje do $6^{\circ}$ pavimento, conforme prescrições da ABNT 7680 (ABNT, 2015). A Tabela 1 apresenta a altura (h) e diâmetro (d) dos testemunhos, os coeficientes de correção devido à relação $h / d\left(k_{1}\right)$, efeito de broqueamento em função do diâmetro $\left(k_{2}\right)$, direção da extração em relação ao lançamento do concreto $\left(k_{3}\right)$ e efeito da umidade do testemunho $\left(\mathrm{k}_{4}\right)$, assim como a resistência inicial $\left(f_{\text {ci,ext,inicial }}\right)$ e corrigida $\left(f_{c i, e x}\right)$. Correspondendo à média dos resultados individuais, a estimativa da resistência característica do concreto $\left(f_{c i, e x t, s e g}\right)$ da laje é cerca de 289 kgf/ $\mathrm{cm}^{2}$, com desvio padrão de $57 \mathrm{kgf} / \mathrm{cm}^{2}$ e coeficiente de variação de $20 \%$.

Apesar dos testemunhos representarem uma amostra do concreto de apenas uma das lajes do edifício, a resistência do material aos 82 anos apresentou um aumento de $74 \mathrm{kgf} / \mathrm{cm}^{2}$ ou $34 \%$ em relação à resistência média obtida aos 28 dias, atendendo às expectativas. 0 desvio padrão e o coeficiente de varia- ção se mantiveram próximos aos valores antigos, considerados elevados por Lobo Carneiro (1944), por tratar-se de obra construída com preocupação em obedecer às boas técnicas construtivas.

\section{ANÁLISE ESTRUTURAL DE LAJE DO PAVIMENTO TIPO}

A genialidade de Baumgart fica ainda

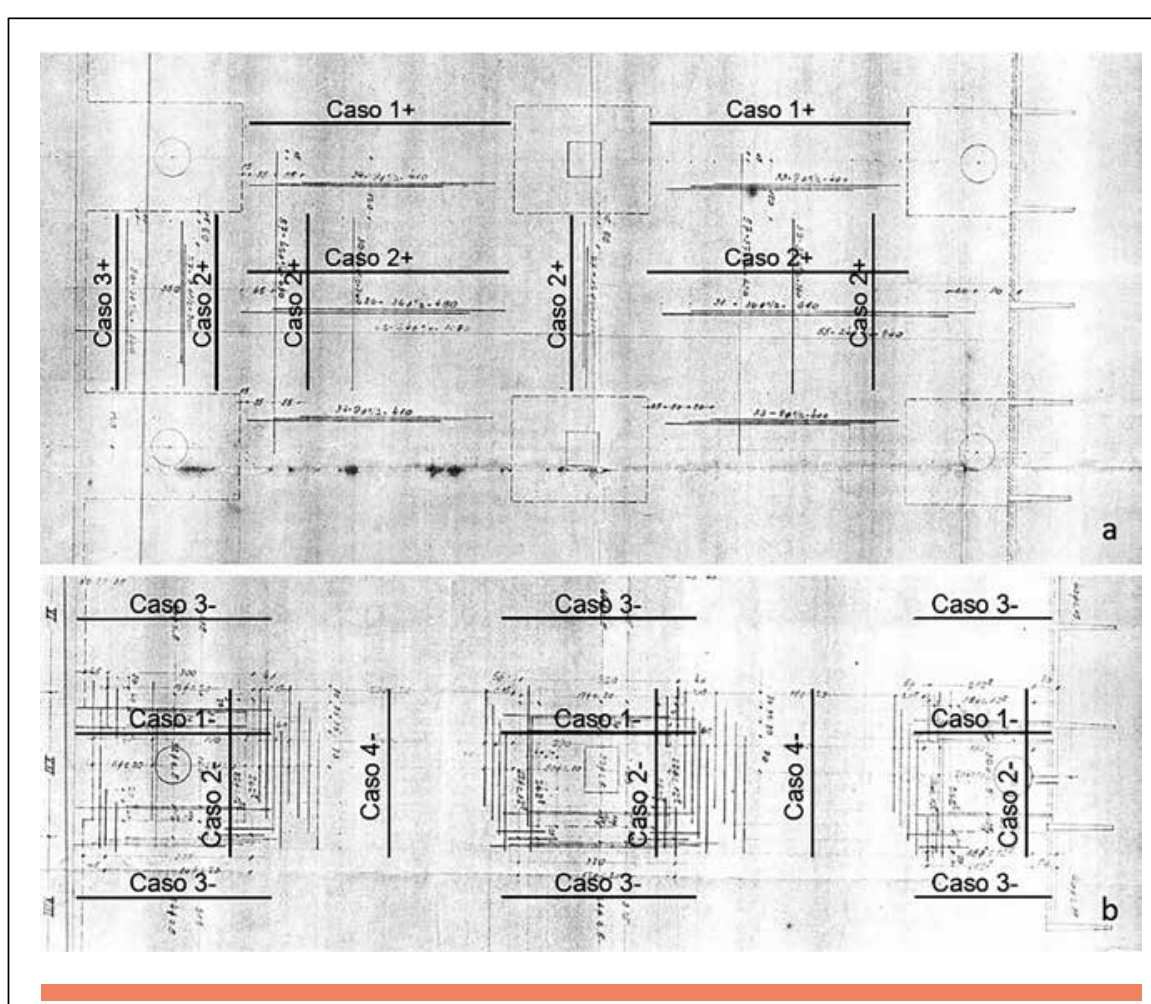

Figura 13

Armaduras da laje: (a) positivas; (b) negativas, adaptado a partir do projeto original de Baumgart, de 1937 
Tabela 2 - Momentos fletores resistentes por metro de laje

\begin{tabular}{|c|c|c|c|c|c|c|c|}
\hline Elemento & Armadura existente & $\begin{array}{c}f_{y k} \\
(\mathrm{MPa})\end{array}$ & $\begin{array}{c}f_{\mathrm{ck}} \\
(\mathrm{MPa})\end{array}$ & $\begin{array}{c}b_{w} \\
(\mathrm{~cm})\end{array}$ & $\begin{array}{c}d \\
(\mathrm{~cm})\end{array}$ & $\begin{array}{c}\mathrm{A}_{\mathrm{s}} \\
\left(\mathrm{cm}^{2} / \mathrm{m}\right)\end{array}$ & $\begin{array}{c}\mathrm{M}_{\mathrm{res}} \\
(\mathrm{kN} \cdot \mathrm{m} / \mathrm{m})\end{array}$ \\
\hline \multicolumn{8}{|c|}{ Flexão positiva } \\
\hline $1^{\circ}$ Caso & $\emptyset 1 / 2 " c / 8,33+\emptyset 1 / 4 " c / 25$ & 240 & 12 & 100 & 15 & 16,47 & 43,21 \\
\hline $2^{\circ}$ Caso & $\emptyset 1 / 2 " c / 12,5+\emptyset 1 / 4 " c / 25$ & 240 & 12 & 100 & 15 & 11,40 & 31,69 \\
\hline $3^{\circ}$ Caso & $\emptyset 1 / 2 " c / 25+\emptyset 1 / 4 " c / 25$ & 240 & 12 & 100 & 15 & 6,34 & 18,52 \\
\hline \multicolumn{8}{|c|}{ Flexão negativa } \\
\hline $1^{\circ}$ Caso & $\emptyset 1 / 2 " c / 5$ & 240 & 12 & 100 & 25 & 25,34 & 112,38 \\
\hline $2^{\circ}$ Caso & $\emptyset 1 / 2 " c / 10$ & 240 & 12 & 100 & 25 & 12,67 & 61,01 \\
\hline $3^{\circ}$ Caso & $\emptyset 1 / 2^{\prime \prime} c / 5$ & 240 & 12 & 100 & 15 & 25,34 & 59,57 \\
\hline $4^{\circ}$ Caso & $\emptyset 1 / 2 " c / 12,5$ & 240 & 12 & 100 & 15 & 10,14 & 28,56 \\
\hline $5^{\circ}$ Caso & $\emptyset 1 / 2 " c / 20$ & 240 & 12 & 100 & 15 & 6,34 & 18,50 \\
\hline
\end{tabular}

mais evidente quando, pelo emprego de um software de elementos finitos para o cálculo das tensões, comparam-se os resultados do processamento de um dos pavimentos tipo do bloco administrativo com as capacidades resistentes da laje em regiões de maior relevância.

Considerando as armaduras detaIhadas nos desenhos do projeto original (Figura 13), a Tabela 2 apresenta os resultados dos momentos resistentes pela laje, calculados conforme o estado atual da arte. A tensão de escoamento adotada para o aço foi de $240 \mathrm{MPa}$, compatível com os aços disponíveis na época, e a resistência à compressão do concreto, 12 $\mathrm{MPa}$, correspondente a 2/3 da resistência requerida de projeto (CARNEIRO, 1944).

Para o cálculo das tensões atuantes, a estrutura do pavimento foi discretizada com elementos tipo Shell e Frame, representando as lajes e vigas, respecti-

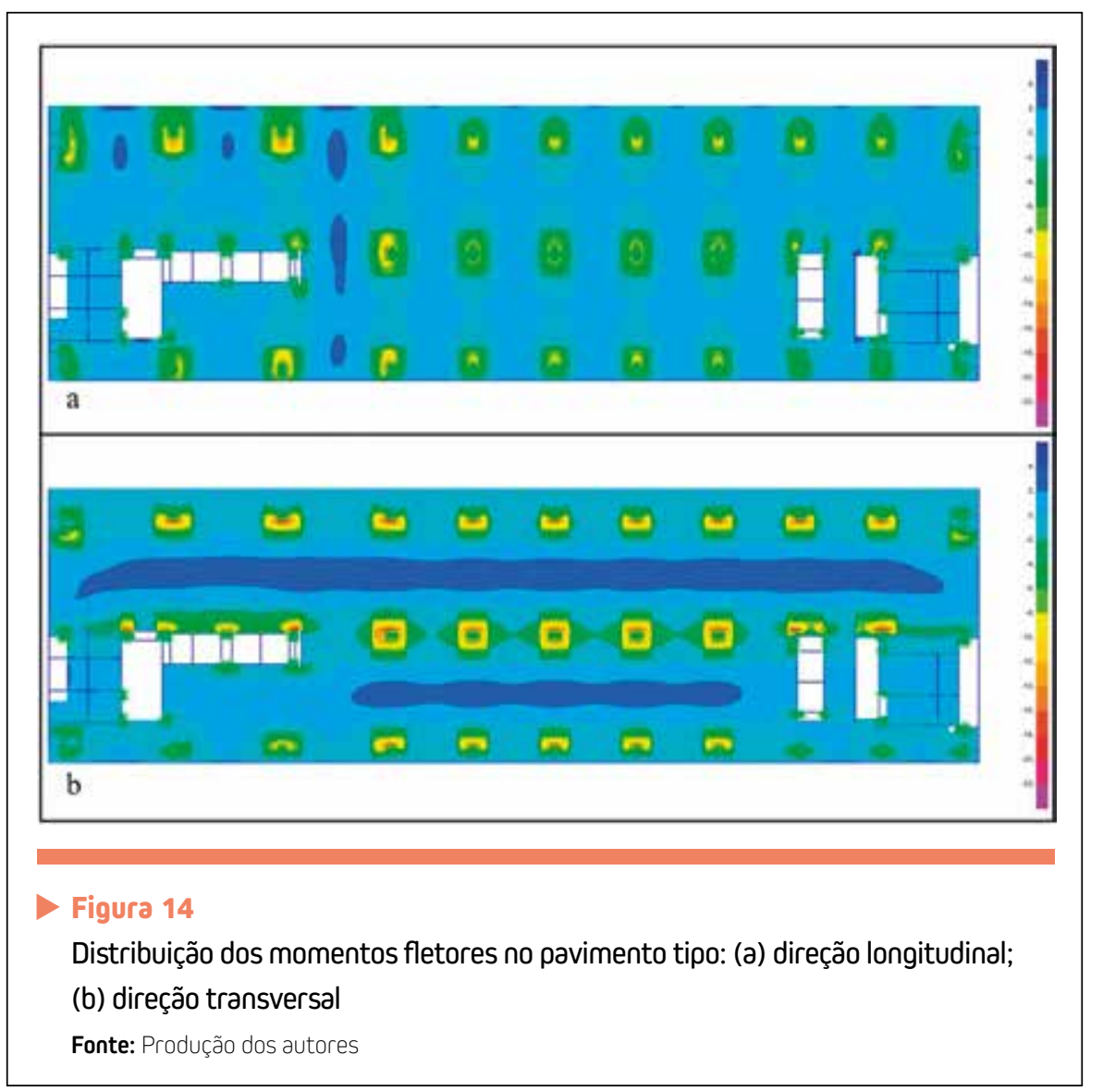

vamente, com as dimensões constantes dos desenhos do projeto estrutural original, em parte preservados.

No tocante às cargas, além do peso próprio, com as demais permanentes obtidas com a composição e espessuras encontradas em pesquisas realizadas no local, considerou-se uma carga acidental de 2,0 kN/m², normalmente utilizada para espaços destinados a escritórios nas últimas décadas, embora haja a suspeita que, no projeto original, o valor adotado para as cargas acidentais tenha sido de $1,5 \mathrm{kN} / \mathrm{m}^{2}$, como preconizado pela antiga norma de cargas para o cálculo de estruturas de edifícios, a NB-5 (ABNT, 1961). Com estas premissas, chega-se aos momentos fletores de cálculo, nas duas direções principais do pavimento, cuja distribuição é apresentada na Figura 14.

A Tabela 3 compara os momentos fletores obtidos no processamento com momentos resistentes, considerando uma região central do pavimento. Tanto para a flexão negativa quanto para a positiva, para efeito de comparação, foram tomados valores nas faixas relativas aos apoios e aos vãos, atuando em ambos os sentidos. As células coloridas de azul mostram seções com suficiente segurança para as cargas consideradas, enquanto as coloridas de vermelho indicam alguma deficiência.

Mais importante que a avaliação da segurança, é a proporcionalidade entre 


\begin{tabular}{|c|c|c|c|c|c|c|c|c|c|}
\hline Elemento & Armadura existente & $\begin{array}{c}\mathrm{f}_{\mathrm{yk}} \\
(\mathrm{MPa})\end{array}$ & $\begin{array}{c}\mathrm{f}_{\mathrm{ek}} \\
(\mathrm{MPa})\end{array}$ & $\begin{array}{c}b_{w} \\
(\mathrm{~cm})\end{array}$ & $\begin{array}{c}d \\
(\mathrm{~cm})\end{array}$ & $\begin{array}{c}\mathrm{As}_{\mathrm{s}} \\
\left(\mathrm{cm}^{2} / \mathrm{m}\right)\end{array}$ & $\begin{array}{c}M_{\mathrm{res}} \\
(\mathrm{kN} \cdot \mathrm{m} / \mathrm{m})\end{array}$ & $\begin{array}{c}M_{\mathrm{s}, \mathrm{d}} \\
(\mathrm{kN} \cdot \mathrm{m})\end{array}$ & $\begin{array}{l}M_{\text {res }} \\
/ M_{\mathrm{s}, \mathrm{d}}\end{array}$ \\
\hline \multicolumn{10}{|c|}{ Flexão positiva } \\
\hline $\mathrm{M}_{\mathrm{T}, \mathrm{p} \text { ilar }}^{+}$ & $\emptyset 1 / 2 " c / 8,33+\emptyset 1 / 4 " c / 25$ & 240 & 12 & 100 & 15 & 16,47 & 43,21 & 30,00 & 1,44 \\
\hline $\mathrm{M}_{\text {T, }}^{+}$ão & $\emptyset 1 / 2 " c / 12,5+\emptyset 1 / 4 " c / 25$ & 240 & 12 & 100 & 15 & 11,40 & 31,69 & 26,50 & 1,20 \\
\hline $\mathrm{M}_{\mathrm{L}, \text { pliar }}$ & $\emptyset 1 / 2 " c / 12,5+\emptyset 1 / 4 " c / 25$ & 240 & 12 & 100 & 15 & 11,40 & 31,69 & 23,00 & 1,38 \\
\hline $\mathrm{M}_{L, \text { Vão }}^{+}$ & $\emptyset 1 / 2 " c / 12,5+\emptyset 1 / 4 " c / 25$ & 240 & 12 & 100 & 15 & 11,40 & 31,69 & 19,00 & 1,67 \\
\hline \multicolumn{10}{|c|}{ Flexão negativa } \\
\hline $\mathrm{M}_{\mathrm{T}, \text { plar }}$ & $\emptyset 1 / 2 " c / 5$ & 240 & 12 & 100 & 25 & 25,34 & 112,38 & 150,00 & 0,75 \\
\hline $\mathrm{M}_{\mathrm{T} \text {,vão }}$ & $\emptyset 1 / 2^{\prime \prime} \mathrm{c} / 5$ & 240 & 12 & 100 & 15 & 25,34 & 59,57 & 72,00 & 0,83 \\
\hline $\mathrm{M}_{\mathrm{L}, \text { pilar }}$ & $\emptyset 1 / 2 " c / 10$ & 240 & 12 & 100 & 25 & 12,67 & 61,01 & 65,00 & 0,94 \\
\hline $\mathrm{M}_{\mathrm{L} \text {,vão }}$ & $\emptyset 1 / 2 " c / 20$ & 240 & 12 & 100 & 15 & 6,34 & 18,50 & 30,00 & 1,62 \\
\hline
\end{tabular}

os valores indicados na coluna direita da Tabela 3, tanto para flexão positiva como negativa, o que mostra a perfeita compreensão do comportamento da estrutura, revelado pelas armaduras detalhadas a mais de oito décadas, numa época em que as ferramentas disponíveis eram as réguas de cálculo e as máquinas de calcular mecânicas.

\section{CONSIDERAÇÕES FINAIS}

A arquitetura do Palácio Gustavo Capanema, como referência do estilo Moderno, gerou demandas para o sistema estrutural consideradas ousa- das para as técnicas de projeto e execução disponíveis na época da construção. As inovações expressivas e bem-sucedidas do projeto elaborado por Emílio Baumgart e o estudo da qualidade do concreto desenvolvido pelo Prof. Lobo Carneiro fazem com que a construção do Palácio Gustavo Capanema seja um exemplo do avanço das soluções construtivas das décadas de 1930 e 1940, com repercussão internacional.

Ensaios em testemunhos extraídos de uma das lajes indicam um aumento de $34 \%$ na resistência média à compressão do concreto, ao longo de 82 anos. A aplicação de técnicas modernas de análise confirma a notável intuição estrutural do projetista na elaboração do projeto das lajes cogumelo invertido.

Com a intervenção em andamento, constata-se que as especificações de projeto foram fielmente atendidas durante o processo construtivo. Assim, a documentação do projeto estrutural e as fotos da construção são frequentemente utilizadas como referência para os projetos da intervenção atual, evitando-se prospecções onerosas e intrusivas, ainda mais indesejáveis por tratar-se de bem tombado.

\section{DREFERÊNCIAS BIBLIOGRÁFICAS}

[1] ABNT, ASSOCIAÇÃO BRASILEIRA DE NORMAS TÉCNICAS. NB-1 - Cálculo e execução de obras de concreto armado. Rio de Janeiro: ABNT, 1946. . NB 5 - Cargas para o cálculo de estruturas de edifícios. Rio de Janeiro: ABNT, 1961. 2015.

[2] ASTORGA. Obras de restauração, conservação e modernização das instalações - Palácio Gustavo Capanema. Projeto de arquitetura. Corte BB. IPHAN. 2020.

[3] CARNEIRO, F. L. L. B. Os coeficientes de segurança e as tensões admissíveis em peças de concreto simples e de concreto armado. In: Symposium de estruturas. Rio de Janeiro: Instituto Nacional de Tecnologia, 1944. v. 2p. 83-126.

[4] COSTA, L. Memorial Descritivo do Projeto do Edifício do Ministério da Educação e Saúde Pública. Rio de Janeiro: Arquivo Central do IPHAN, 1936. 10 flhs.

[5] COSTA, T. Engenharia da transparência - vida e obra de Fernando Lobo Carneiro. Rio de Janeiro: COPPE-UFRJ, 2005.

[6] FAUSTO, Boris. História do Brasil. São Paulo: Editora da Universidade de São Paulo, 2007. 12 ed. 2 reimpr. 660 pg.

[7] LAURD, LABORATÓRIO DE ARQUITETURA E URBANISMO. Dossiê Ministério da Educação e Saúde. Rio de Janeiro. Coordenador Acadêmico Prof. Dr. Roberto Segre. Programa de Pós-Graduação em Urbanismo. Faculdade de Arquitetura e Urbanismo. Universidade Federal do Rio de Janeiro, 2009.

[8] LEAL, J. L. Fotos do Palácio Gustavo Capanema. 2018 a 2020. Acervo pessoal.

[9] LISSOVSKY, M.; SÁ, P. S. M. DE. Colunas da educação - a construção do Ministério da Educação e Saúde, 1935-1945. Rio de Janeiro: MINC/IPHAN; FGV/CPDOC, 1996. $335 \mathrm{pg}$.

[10] MARTINELLI, F. D. Entre o concreto e o papel: a memória arquitetônica do Palácio Gustavo Capanema. 189 p. Mestrado em Preservação do Patrimônio Cultural, Instituto do Patrimônio Histórico e Artístico Nacional, Rio de Janeiro, 2017.

[10] SEGRE, R.; BOAS, N. V.; SOUZA, L. T. 0 Ministério da Educação e Saúde Pública (1935-1945) - As inovações climáticas e tecnológicas. Anais do 8 DOCOMOMO Brasil, 2009, Rio de Janeiro. Cidade Moderna e Contemporanea - Paradoxo e Síntese das Artes. Rio de Janeiro: PROURB, 2009

[12] THOMAZ, E. C. S. Notas de aula sobre Emílio Baumgart. Rio de Janeiro: Instituto Militar de Engenharia, 2015.

[13] VASCONCELOS, A. C. 0 concreto no Brasil - recordes, realizações, história. 2a ed. São Paulo: Pini, 1992. 